\title{
A COMPARISON OF THE MAMMALIAN AND REPTILIAN TECTA
}

\author{
G. CARL HUBER AND ELIZABETH C. CROSBY
}

Department of Anatomy, University of Michigan

ELEVEN FIGURES

Although the present group of papers is concerned chiefly with the tegmental and isthmus regions of the midbrain, a brief résumé of the tectal pattern in mammals, with comparisons with that seen in reptiles, may not be amiss. This is more particularly true since the part of this series of papers dealing with the fiber paths of the midbrain is introduced by a detailed account of many of the tectal connections in a wide range of mammals. Moreover, an understanding of the significance of the mammalian pattern is facilitated by a comparison of it with that seen in submammalian brains.

STRATA OF THE MAMMALIAN OPTIC TECTUM

Like other regions in the nervous system, the mammalian optic tectum has been subdivided differently by various observers, depending upon the animals studied and the particular relations the worker was seeking to emphasize. In the present account, a nine-layered pattern, similar to that described by Tsai ('25) for the marsupial, has been used as a basis for description. Table 1 is a summary of the chief characteristics of the layers of the superior collicular portion of the tectum in certain representative mammals, as revealed in toluidin blue, pyridine silver and Weigert preparations. These layers are illustrated in figures 1 to 3 and figures 7, 9 and 10 for the mammals indicated in the figure descriptions.

Table 1. A descriptive tabulation of the layers of the optic tectum in representative mammals, based on a study of cell and fiber preparations from the Huber Neurological Collection. 


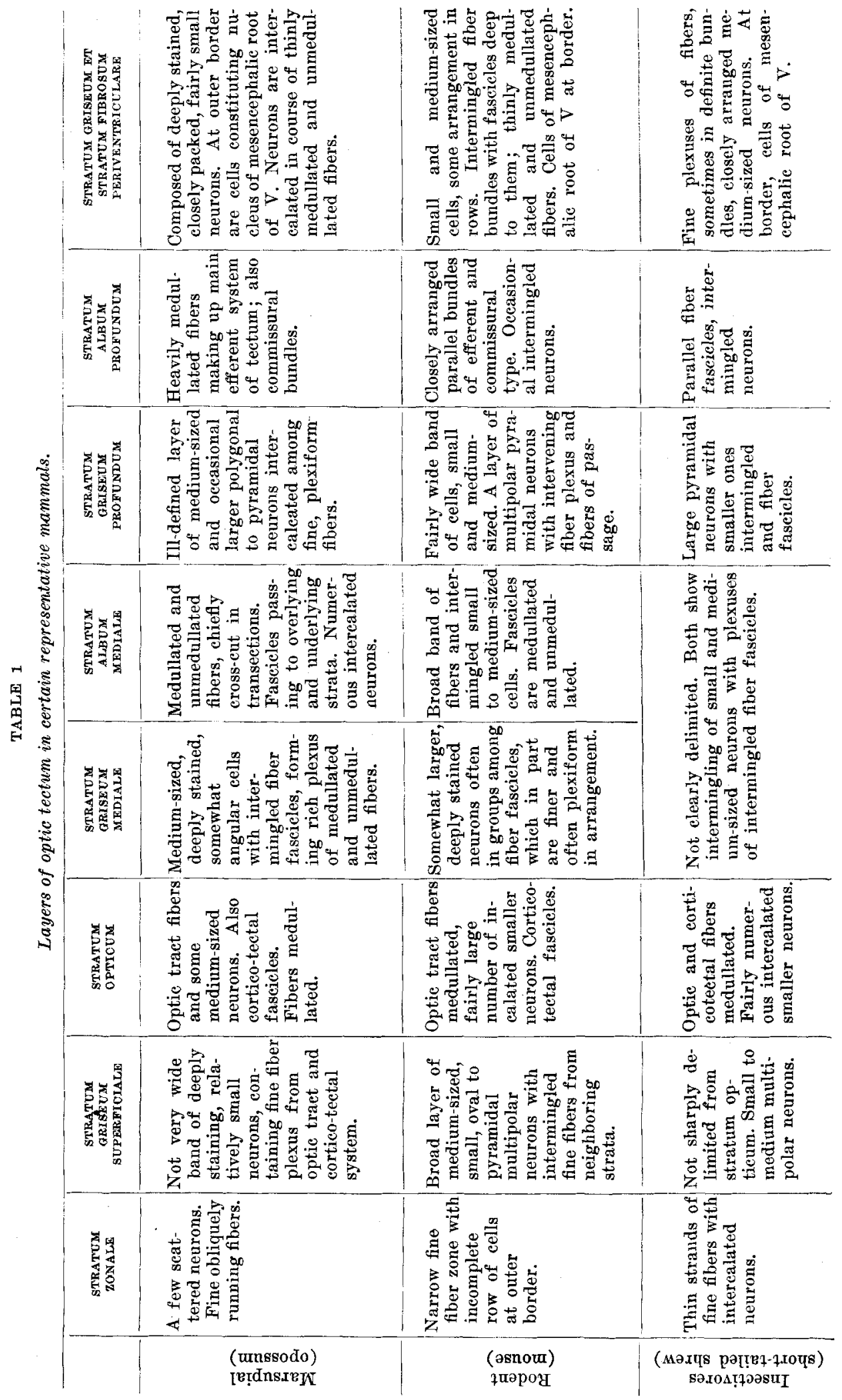




\begin{tabular}{|c|c|c|}
\hline 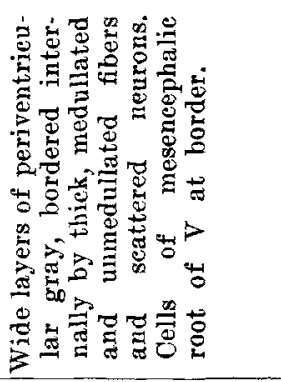 & 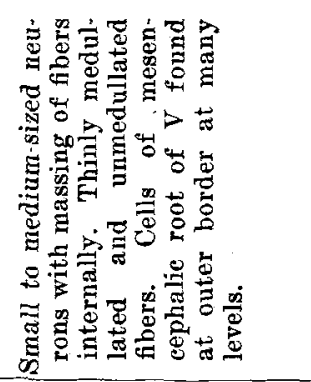 & 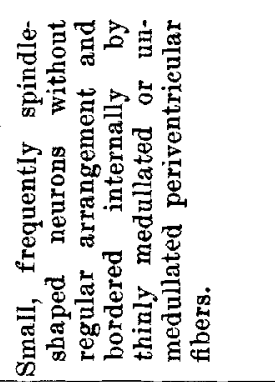 \\
\hline 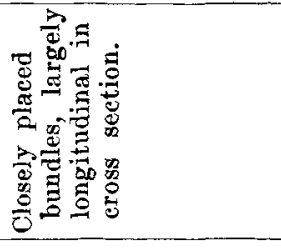 & 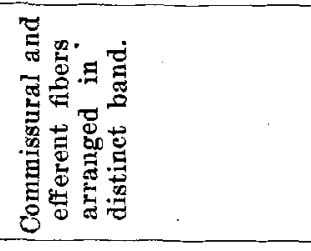 & 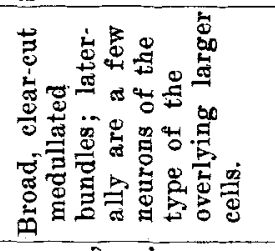 \\
\hline 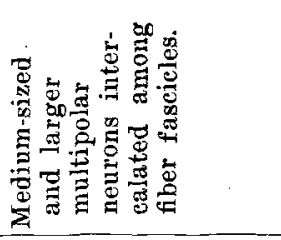 & 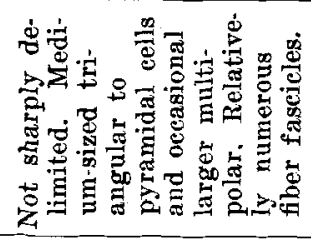 & 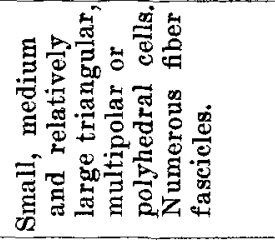 \\
\hline 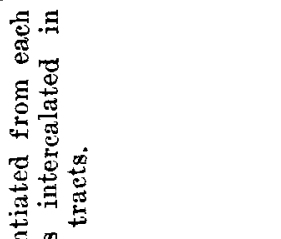 & 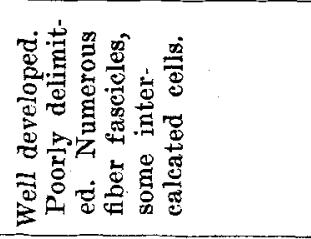 & 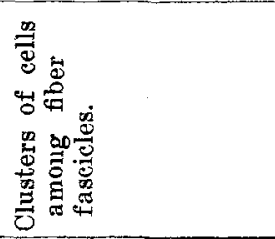 \\
\hline 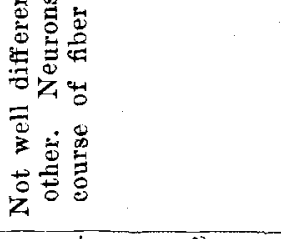 & 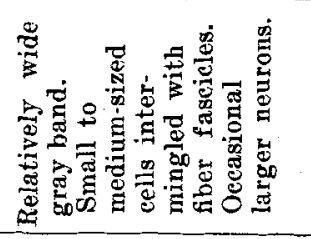 & 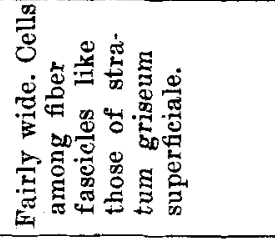 \\
\hline 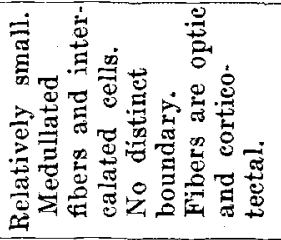 & 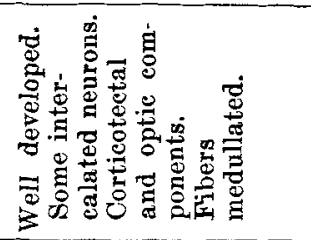 & 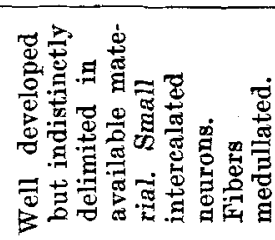 \\
\hline 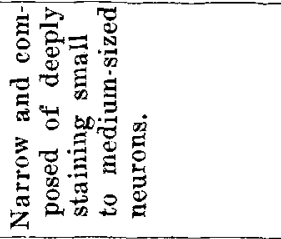 & 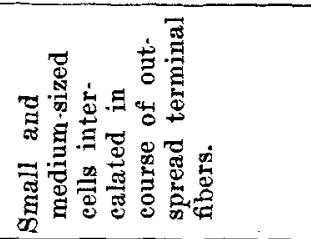 & 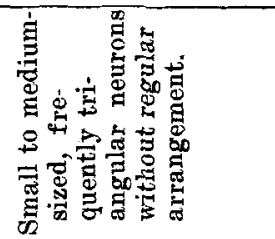 \\
\hline 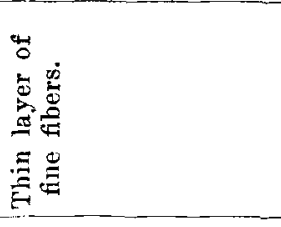 & 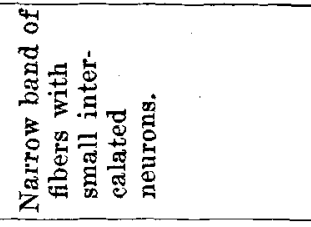 & 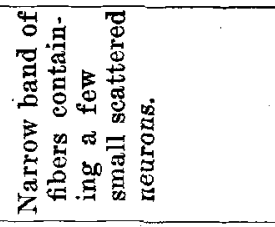 \\
\hline 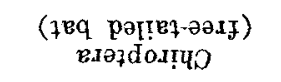 & 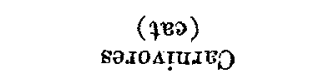 & 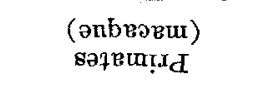 \\
\hline
\end{tabular}


The following paragraphs list some of the more usual names used for them in the various languages. No attempt has been made to present a complete account of the terminology.

1. Stratum zonale. This corresponds to fibrille periferiche of Tartuferi (1885), stratum zonale of Obersteiner ('01), Marburg ('04), Bailey, Strong and Elwyn ('25) and Ranson ('40) for man, Ramón y Cajal ('11) and Winkler and Potter ('11 and '14) for the rabbit and the cat and Tsai ('25) for the opossum, äussere weisse Lage of von Kölliker (1896) for the rabbit and the cat, $W_{1}$ of Frankl-Hochwart ('02) for the mole and strato marginale of Castaldi ('23) for the guinea pig.

2. Stratum griseum superficiale. This stratum is comparable to cappa cinerea of Tartuferi (1885) for man and Castaldi ('23) for the guinea pig, zona grisea superficialis of Obersteiner ('01) for man, die äussere graue Lage of von Kölliker (1896) for the eat and the rabbit, $G_{1}$ of FranklHochwart ('02) for the mole, erste graue Schicht of Marburg. ('04) for man, stratum griseum superficiale of Winkler and Potter ('11 and '14) for the rabbit and the cat and Tsai ('25) for the opossum, zone cenree of Ramón y Cajal ('11) for the rabbit and the eat, stratum cinereum of Bailey, Strong and Elwyn ('25) for man, and stratum griseum of Ranson ('40) for man.

3. Stratum opticum. This layer is represented in the outer part of strato bianco cinereo superficiale of Tartuferi (1885) for man, in die mittlere weisse Lage of von Kölliker (1896) for the rabbit and the cat, in $\mathrm{W}_{1}$ of Frankl-Hochwart ('02) for the mole, in stratum opticum of Marburg ('04) and Ranson ('40) for man and Tsai ('25) for the opossum, in stratum medullare superficiale of Winkler and Potter ('11 and '14) for the rabbit and the cat, and Bailey, Strong and Elwyn ('25) for man, in zone des fibres optique of Ramón y Cajal ('11) for the rabbit and the cat and in strato ottico of Castaldi ('23) for the guinea pig.

4. Stratum griseum intermediale. This corresponds to the mittlere graue Lage of von Kölliker (1896) for the rabbit and the cat, $\mathrm{W}_{2}$ of Frankl-Hochwart ('02) for the mole, die zweite 
graue Schicht of Marburg ('04) for man, stratum griseum intermedium of Winkler and Potter ('11 and '14) for the rabbit and the cat, strato bianco cinereo superficiale of Castaldi ('23) for the guinea pig, stratum griseum medius of Tsai ('25) for the opossum, and stratum griseum mediale of stratum lemnisci of Bailey, Strong and Elwyn ('25) for man.

5. Stratum album intermediale. This is represented in the innere weisse Lage of von Kölliker (1896) for the cat and the rabbit, $\mathrm{W}_{3}$ of Frankl-Hochwart ('02) for the mole, stratum lemnisci of Marburg ('04) for man, stratum medullare intermedium of Winkler and Potter ('11 and '14) for the rabbit and the cat, strato sensitivo ascendenti of Castaldi ('23) for the guinea pig, stratum album medius of Tsai ('25) for the opossum and stratum medullare mediale of stratum lemnisci of Bailey, Strong and Elwyn ('25) for man.

6. Stratum griseum profundum. This stratum appears to correspond to the innere graue Lage of von Kölliker (1896) for the cat and the rabbit, $W_{4}$ of Frankl-Hochwart ('02) for the mole, die dritte graue Schicht of Marburg ('04) for man, stratum griseum profundum of Winkler and Potter ('11 and '14) for the rabbit and the cat and Tsai ('25) for the opossum, strato bianco cinereo profondo of Castaldi ('23) for the guinea pig and stratum griseum profundum of stratum lemnisci of Bailey, Strong and Elwyn ('25) for man.

7. Stratum album profundum. This is the homologue of das tiefe Mark of Marburg ('04) for man, stratum medullare profundum of Winkler and Potter ('11 and '14) for the rabbit and the cat, midollo profondo of Castaldi ('23) for the guinea pig, stratum album profundum of Tsai ('25) for the opossum and stratum medullare profundum of stratum lemnisci of Bailey, Strong and Elwyn ('25) for man.

8 and 9. Stratum griseum periventriculare and stratum fibrosum periventriculare. These strata are represented in grigio central and strato germinativo of Castaldi ('23) for the guinea pig. Most students of mammalian brains have not considered the periventricular layers as a part of the optic tectum. Often they have been included in the central gray 
(for example, by Ranson, '40, page 159), for which they constitute a pars dorsalis (for example, see the Crosby and Woodburne paper, ' $43 \mathrm{~b}$ on the bat and the shrew).

Frequently, certain of the preceding strata have been grouped into a single layer. Thus stratum opticum, stratum griseum intermediale and stratum album intermediale have been called strato bianco cinereo superficiale by Tartuferi (1885). Ramón y Cajal ('11) combined stratum griseum intermediale and stratum album intermediale under the name of zone ganglionnaire ou des fibres horizontales, and stratum griseum profundum and stratum album profundum under the term zone de la substance grise centrale. All of the layers from stratum griseum intermediale to stratum album profundum inclusive have been considered subdivisions of stratum lemnisci by Bailey, Strong and Elwyn ('25). Ranson ('40) applied the name stratum lemnisci to the outer two of these layers, stratum griseum intermediale and stratum album intermediale. It is not clear as to exactly which region he intended to designate by his stratum profundum, since his text ('40, page 162) and his figure (fig. 116) do not appear to correspond.

In general the combinations of layers made by various workers, as indicated in the preceding paragraph, are justified for the forms considered. It should be emphasized that the ease, or difficulty, with which these layers can be delimited differs in the forms under consideration depending upon various factors, primarily upon the size of the optic connections, but also upon the degree of development of the corticotectal systems and, to some extent, upon the place of the animal in the mammalian series. A well developed optic tract and associated cortico-tectal bundles constituting the optic stratum differentiate clearly the superficial from the intermediate gray layer, but if the eyes are small and the optic stratum correspondingly reduced, as in the bat and the shrew, the separation of these gray layers is much less clear. Internal cortico-tectal tracts and ascending systems from lower centers tend to break up into bundles which spread out in the region 
between stratum opticum and stratum album profundum, so that these strata may not be so well demarcated in this region, justifying their inclusion within a single layer, as certain observers have done, particularly for man (Bailey, Strong and Elwyn, '25, for example).

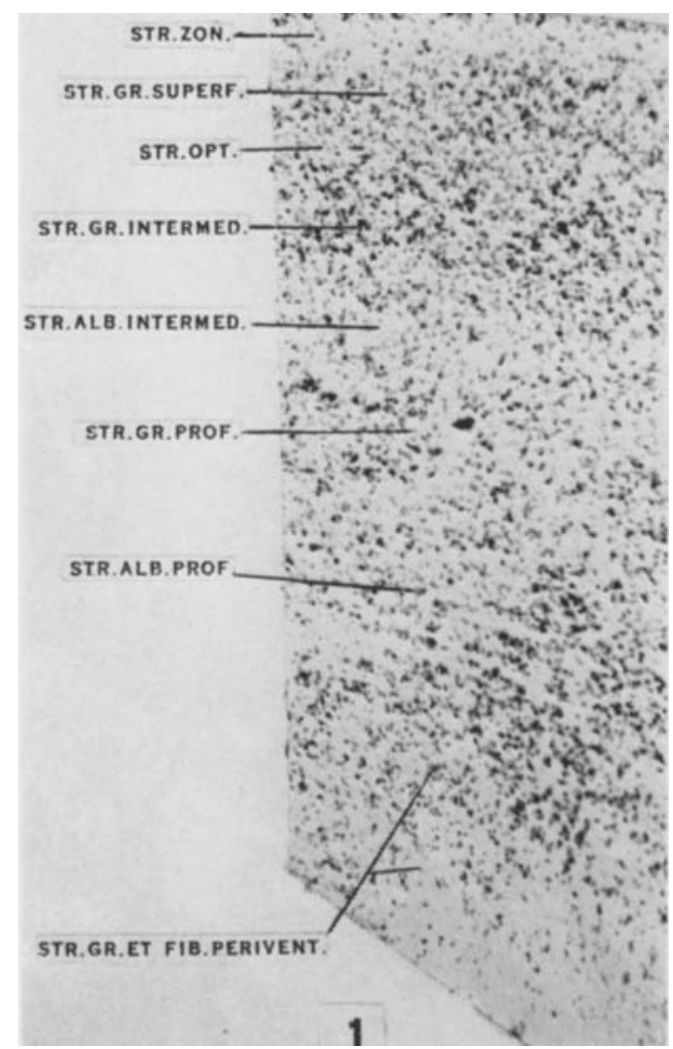

Fig. 1 Photomicrograph of a narrow transverse band through the optic tectum of the short-tailed shrew, showing the tectal pattern. Toluidin blue preparation. $\times 50$.

Throughout the series, stratum zonale (figs. 1 to $3,7,9$ and 10 ) is a narrow band containing fine fibers which turn down into the underlying gray. The work of Probst ('01), Mettler ('32), Barris, Ingram and Ranson ('35) and others, which 


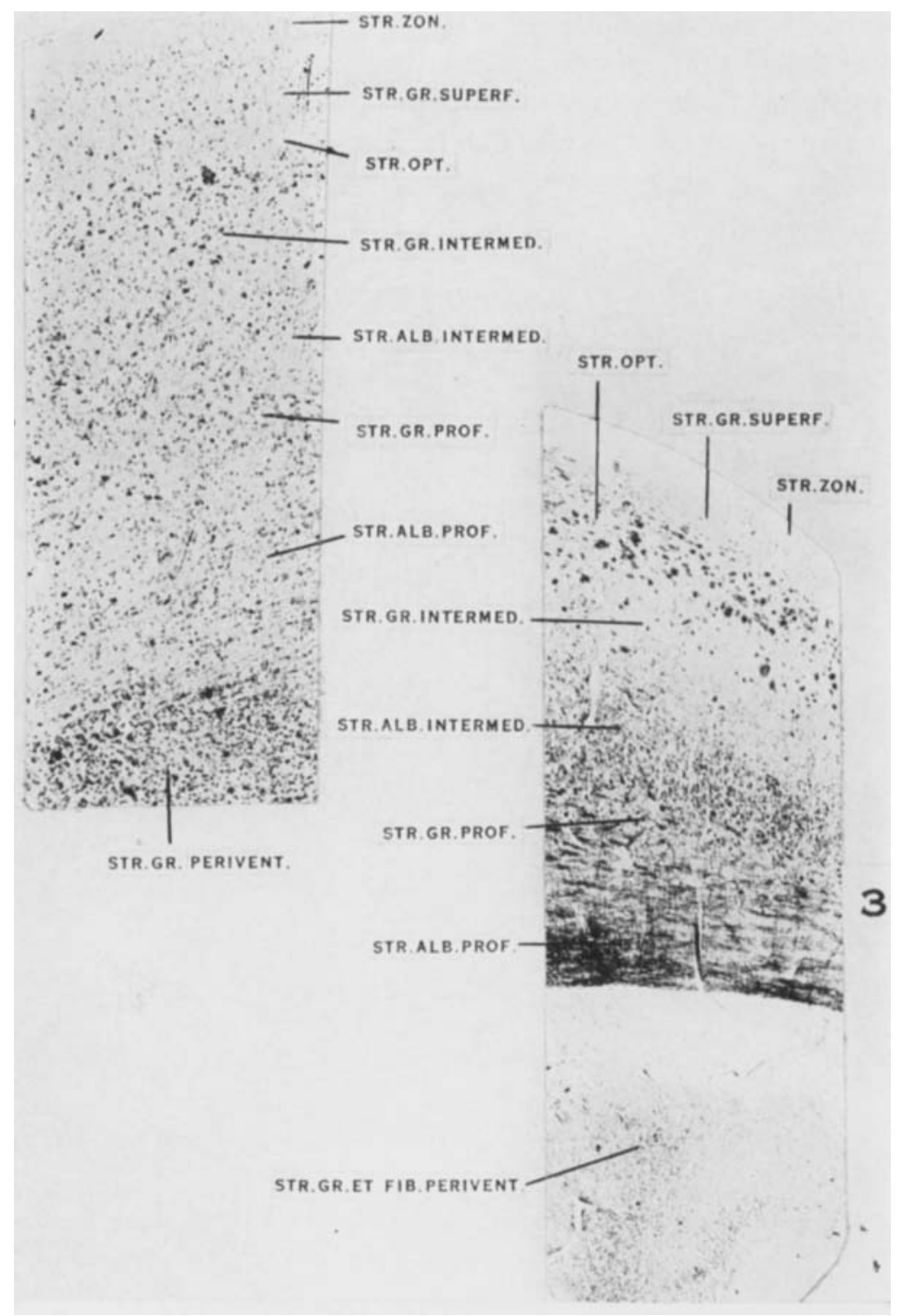

F'ig. 2 Photomierograph of a narrow transverse band through the optic tectum of the cat, in which the arrangement of the tectal strata are indicated. Toluidin blue preparation. $\times 20$.

Fig. 3 Photomicrograph of a narrow band eut transversely through the optic tectum of the macaque, to show the arrangement of the tectal layers. Weigert preparation. $\times 15$. 
our own observations have confirmed, indicates that, in many mammals, this stratum contains cortico-tectal fibers - the external cortico-tectal tract of this account. Stratum zonale may be very narrow, many of such fibers may terminate directly in stratum griseum superficiale without accumulating at the surface, or they may assemble in stratum zonale at the rostral end of the midbrain and farther caudalward cut through stratum griseum superficiale (distributing to it) to lie on the upper surface of the optic tract, but still in relation to superficial gray. Various observers have thought that stratum zonale and the bundles in the superficial gray consisted of optic fibers. Thus Loepp ('12) and Brouwer and his associates ('23, '27) found degeneration of the superficial gray of the optic tectum after interruption of the primary optic system in the rabbit. However, a considerable number of workers with experimental material (Probst, '01; Ramón y Cajal, '11; Mettler, '32; Barris, Ingram and Ranson, '35) have been unable to demonstrate optic tract fibers in stratum zonale, but have found degeneration in this area following cortical lesions (Probst, '01, p. 42, fig. 3; Mettler, '32; Barris, Ingram and Ranson, '35, p. 149, fig. 14). The last mentioned group of observers, who regarded these fibers as collaterals of the more deeply located cortico-tectal tract, found such fibers in stratum zonale only in its rostral portion in the cat. Farther caudalward such fascicles cut through to form the upper layer of stratum opticum in the fashion mentioned at the opening of this paragraph, an arrangement which varies somewhat from form to form. For the purpose of the present paper the significant fact is the presence of such fibers in the optic tectum in relation to the superficial gray.

Stratum griseum superficiale (figs. 1 to $3,7,9$ and 10) is frequently broken up by numerous fascicles, significantly of cortico-tectal character, among which are typically smallsized cells. It varies in thickness in different mammals, being thin, for example in the shrew. It may also vary in thickness in different parts of the same optic tectum. Thus it is thick over the convexity of the human superior colliculus but thin at the lateral edge and interrupted in the midline. 
Stratum opticum (figs. 1 to $3,7,9$ and 10) carries optic tract and cortico-tectal fibers. It is usually large in animals having large eyes. From this stratum optic collaterals may enter overlying gray but the fibers turn, mainly, deep into the optic tectum. Associated with its under border and usually considered, then, as its deep layer (courant profound, Ramón y Cajal, '11, p. 181, fig. 122) is a cortico-tectal system (Probst, '01; Ramón y Cajal, '11; Mettler, '32; Barris, Ingram and Ranson, '35). Even in normal material the cortico-tectal character of these fascicles, the internal cortico-tectal tract of the present account, has been easily documented for a wide series of mammals, but the writers have not been able to trace them to their exact origin from the cortex. The present indication from studies in progress is that they come not only from occipital regions but from other cortical areas as well. This would be in line with the results reported by Mettler ('32). That some of them may be fibers of passage to the inferior colliculus (Mettler, '32; see also Barris, Ingram and Ranson, '35) offers very interesting possibilities but needs further documentation in other mammals.

The next three layers (figs. 1 to $3,7,9$ and 10) - stratum griseum intermediale, stratum album intermediale and stratum griseum profundum - represent receptive and correlative areas for certain of the ascending systems (such as the spino-tectal tract) to the optic tectum and terminals of the optic system, and constitute an area of reception for the internal cortico-tectal tract from the occipital and other regions of the hemisphere.

These strata differ, then, particularly in regard to the number of included medullated fibers, with the size of the ascending systems and the internal cortico-tectal tract. This tract forms a considerable part of the medullated fibers in this area, especially in stratum griseum intermediale. The strata under consideration vary also in size, especially in the development of the outer gray layer, with that of the optic tract, since the importance of this optic system in the superior 
collicular region is reflected in the richness of correlation between incoming optic impulses and those carried by entering fiber systems from lower brain levels, such as the spinotectal bundle and the collaterals of the ventral secondary ascending tract of $\mathrm{V}$, both of which have been demonstrated to terminate in the optic tectum in various members of the group considered. These three strata - and particularly stratum griseum intermediale and stratum album intermediale - are not clearly separated from each other in certain mammals (especially in the bat, the shrew and primates) due to the wide spread of entering fascicles.

Stratum album profundum (figs. 1 to 3,7 and 9 ) is well developed throughout the series and is composed chiefly, probably entirely, of efferent and commissural fibers. The cell bodies of the neurons giving rise to these efferent fibers are situated in the overlying stratum griseum profundum and stratum griseum intermediale and in the underlying stratum griseum periventriculare. Stratum album profundum is smaller in general in those mammals in which the superior colliculus, due to the reduction of the eyes, dominates less completely the roof of the midbrain, as in the bat and the shrew. It is very large in animals, such as the monkey, in which eyes have a dominant rôle in the reflexes of the animal.

The periventricular layers of the optic tectum (figs. 1 to 3 , 7 and 9) are represented in pars dorsalis of the central gray. During the course of ontogenetic (Barnard, '38) as well as phylogenetic (Huber and Crosby, '33 a, and elsewhere) development, these layers have retained their primitive position near the ventricle and their relations with the hypothalamic areas by a periventricular fiber system. They are well represented in the mammals considered, and have an intimate relation with the chief nucleus of the inferior colliculus. Their relations to lateral and ventral parts of the central gray have been discussed in other papers in this series and need not be considered here. 


\section{RÉSUMÉ OF CERTAIN FIBER CONNECTIONS OF THE MAMMALIAN OPTIC TECTUM}

In table 2, certain major connections of the mammalian optic tectum are listed and reference to many of these has already been made in the present account of the layers of this region in mammals. This list gives only the more generally recognized fiber connections, for most of which there is ample documentation in the literature. Moreover, they have been verified by the authors in a rather wide range of mammals. The second part of this series of papers, which deals with the fiber connections of the mammalian midbrain, contains descriptions of these systems in normal and, in many cases, in experimental animals, along with numerous accounts of other connections, some of which have not been previously described. It also gives as full reference as possible to previous descriptions so that such review need not be given here. Those connections considered here are sufficiently well known to serve the purposes of the present paper - which is to present the general pattern of the mammalian optic tectum without further description or illustration.

A survey of its nuclear pattern and the fiber paths listed in table 2 suggests certain important connections of the optic tectum.

1. Its dominant entering sensory system in most mammals is the optic tract. The details of distribution of the optic fibers to the superior colliculus will be left for later consideration. It is important to note here, however, that this tract contributes particularly, by deeply running fibers, to the underlying layers intervening between it and stratum album profundum, a condition comparable to that seen in reptilian forms.

2. Spino-tectal fascicles and collaterals of the ventral secondary ascending tract of $\mathrm{V}$ distribute to the mammalian optic tectum, but the spino-thalamic tracts and the main fascicles of the ventral secondary ascending fibers of $V$ terminate directly in the ventral nucleus of the dorsal thalamus, as do also the dorsal secondary ascending tract of $\mathrm{V}$ and the medial lemniscus. 
3. Interconnections between the thalamic regions and the optic tectum are not highly developed in mammals. Bodian ('40) described fiber fascicles in the opossum connecting the optic tectum with the ventral nucleus of the dorsal thalamus; Rioch ('31) pointed out a similar connection for the aevisa and, recently, Rose (' 42 a) found these fibers in the rabbit. The authors have been able to verify such a connection in several subprimates but have not succeeded as yet in identifying it in primates, in which forms nevertheless it quite possibly may persist. An efferent tecto-thalamic tract (a component of the peduncle of the superior colliculus) is present in mammals which have a ventral nucleus of the lateral geniculate body (see also Ariëns Kappers, Huber and Crosby, '36). This phylogenetically old bundle has not been identified in the highest mammals, which lack (except for possible vestiges) a ventral nucleus of the lateral geniculate. In the forms in which it is present, this ventral nucleus serves as a way station for efferent impulses from the optic tectum to the brain stem, the connection being established by tecto-geniculate fibers from the optic tectum to the ventral nucleus of the lateral geniculate body, and by fasciculus geniculatus descendens from this latter nucleus to lower centers, either directly or after a synapse in the tegmentum of the midbrain or pons. Still other connections, some of them of relatively minor importance, have been described between the optic tectum and the diencephalic regions rostral to it. Incerto-tectal fibers were identified by Gurdjian ('27) and Rioch ('29 b) in the rat and the dog, respectively. Interconnections with the pretectal nucleus have

Table 2. This table is intended to contrast the fiber connections characteristic of the various strata of the reptilian optic tectum with those typifying the corresponding regions in mammals. The documentation of the connections listed for reptiles is to be found in the 1933 a paper of Huber and Crosby, where the pertinent literature is also discussed. The connections listed in this table for mammals have been traced by the authors in serially-cut fiber preparations for a rather wide range of mammalian forms. Since these connections are not illustrated in the present paper, the tracts not so widely deseribed have been further documented by a selected reference to the literature. These and other tectal connections are described and illustrated, with suitable consideration of the literature, in Part II of the present series of papers, which deals with the fiber connections. 


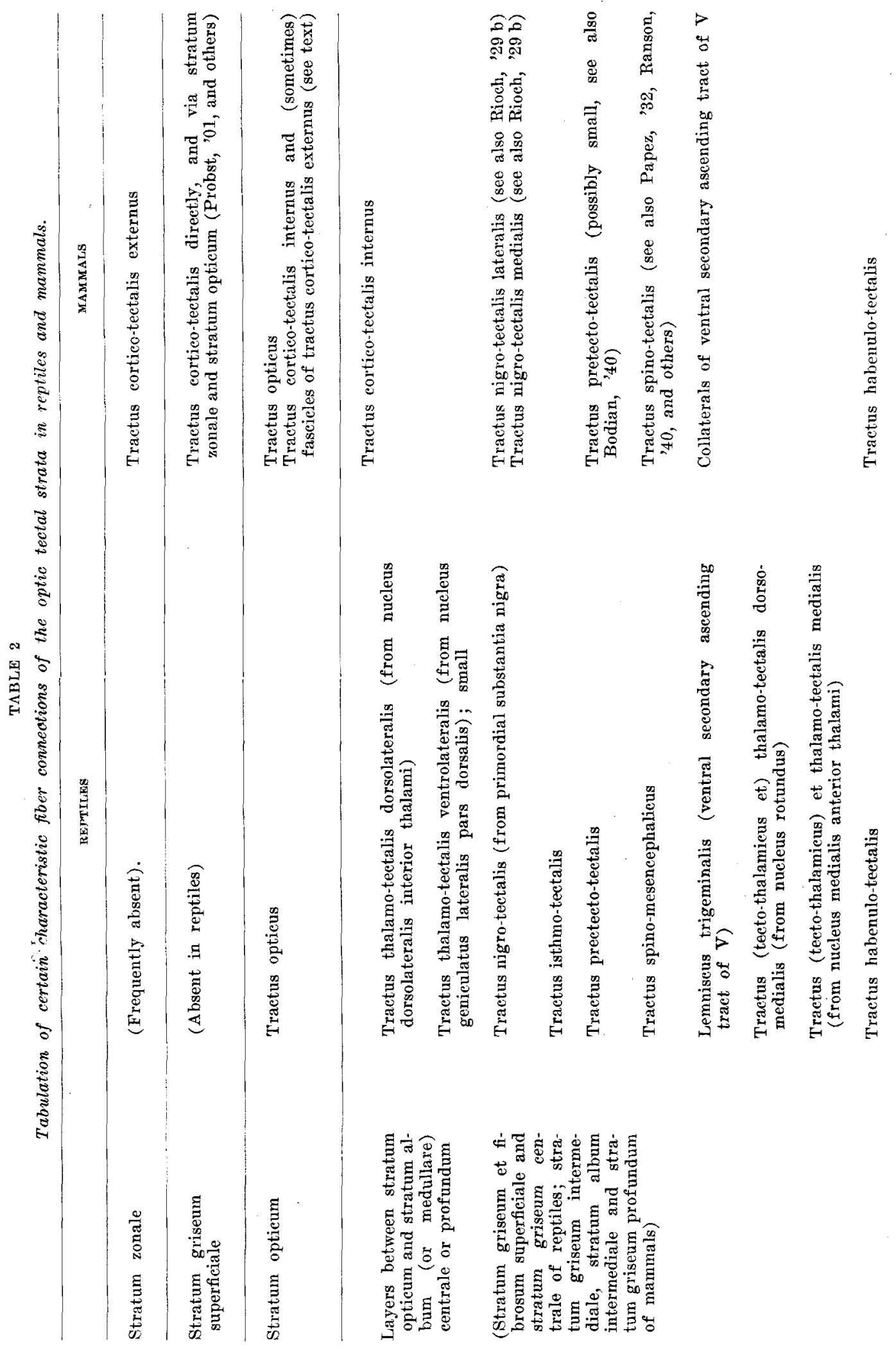



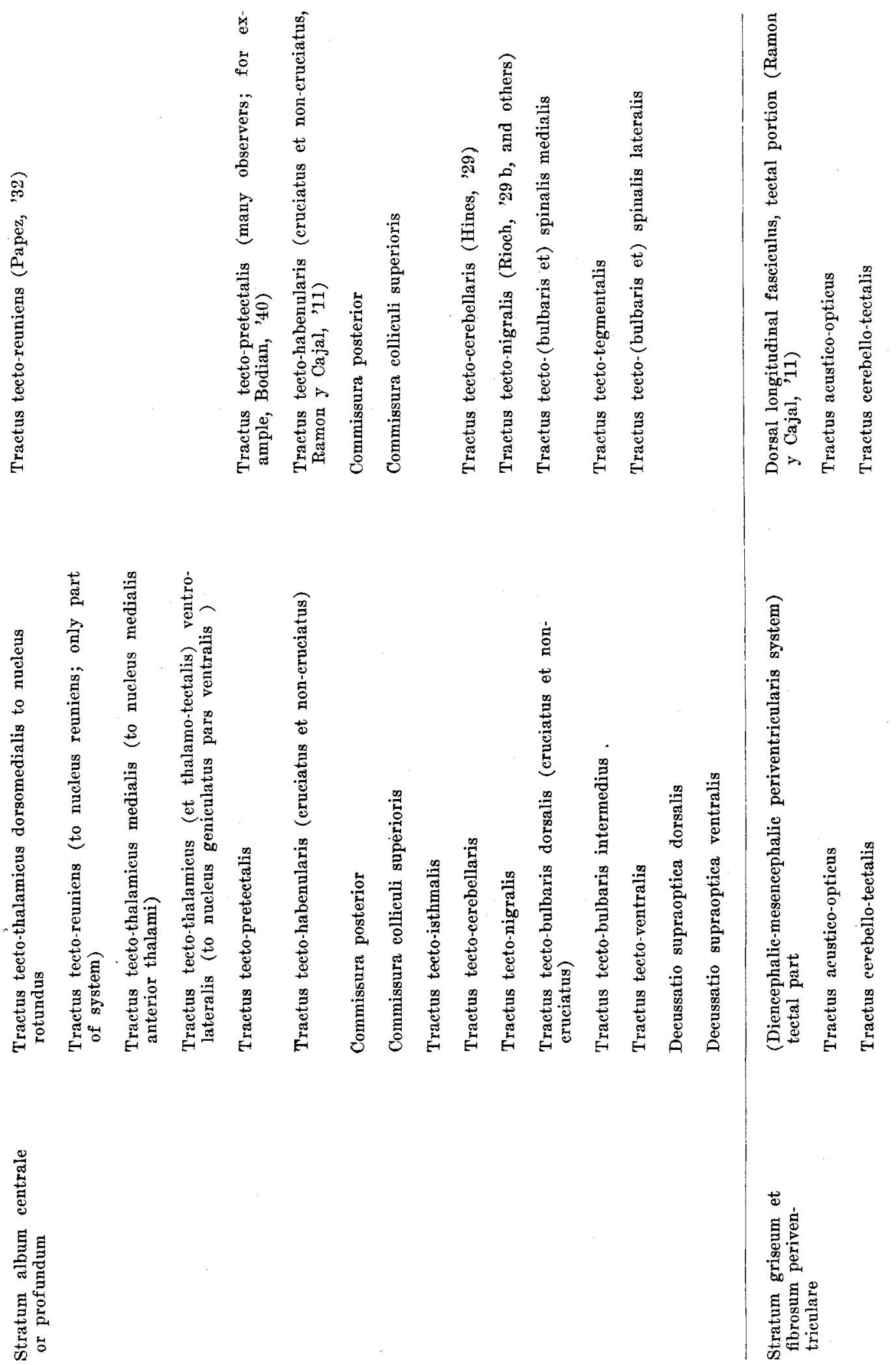
been recognized by many students of the diencephalic-mesencephalic transition regions.

It would appear that the optic tectum in mammals is not an important way station to the dorsal thalamus for pain and temperature impulses, which is one of its important functions in lower forms, although such impulses still reach it in mammals to provide the sensory components of the reflex arcs mediated through this portion of the midbrain roof. The efferent components of such reflex arcs are cared for through tecto-bulbar, tecto-tegmental and tecto-spinal systems and, in many subprimates, also through tecto-geniculate fascicles and fasciculus geniculatus descendens.

5. Of especial significance in the functioning of the mammalian optic tectum are its cortico-tectal connections. These permit the cortical conditioning of visual and other tectal reflexes. The optic tectum becomes, then, an important region of synapse in the extrapyramidal system. The term extrapyramidal is used here in its widest sense, implying any neurons, other than those of the pyramidal tract, which connect the cortex with efferent centers of the brain stem or spinal cord. The optic tectum receives at least two corticotectal systems in many mammals. One of these, the internal cortico-tectal tract, arises from near the occipital pole and probably other regions (compare Mettler, '32; and LeGros Clark, '42). Much smaller external cortico-tectal fascicles (according to Barris, Ingram and Ranson, '35, probably collaterals of the other fibers) break up in the most superficial gray stratum of the optic tectum. These systems permit impulses to pass from the cortex, via a synapse in the optic tectum, to eye-muscle nuclei and to centers supplying neck mucles, for regulating and conditioning visual and other reflexes. Impulses leading to conjugate deviation of the eyes to the opposite side, following stimulation of various cortical areas in certain mammals (Fulton, '38), quite probably pass, for a part of their course, over cortico-tectal fascicles arising from frontal, temporal and occipital regions of the cortex. 
STRATA OF THE REPTILIAN OPTIC TECTUM

Many years ago, Pedro Ramón (1896) described and illustrated beautifully the marked lamination characteristic of the reptilian optic tectum. Since that time, various observers have noted and figured this characteristic arrangement in reptilian and avian forms. The fourteen layers found in the chameleon by Ramón were documented by Huber and Crosby (' 33 a) in a considerable range of reptilian material and regrouped by them into six major regions or laminae. To these layers they applied the names of stratum opticum, stratum fibrosum et griseum superficiale (or griseum et fibrosum), stratum griseum centrale (profundum), stratum album centrale (profundum), stratum griseum periventriculare and stratum fibrosum periventriculare (fig. 6). These two last mentioned strata may be intermingled to some extent. Some reptiles, and certain subreptiles, but not all, have also a narrow peripheral stratum zonale. Later, these observers (Huber and Crosby, '33 b and ' $34^{1}$; Ariëns Kappers, Huber and Crosby, '36) applied this pattern to the arrangement seen in various submammals.

\section{RÉSUMÉ OF CERTAIN FIBER CONNECTIONS OF THE REPTILIAN OPTIC TECTUM}

Table 2 gives certain major fiber connections of the various layers, documentation for which will be found in the 1933 a paper on the reptilian tectum by Huber and Crosby. In this paper, the pertinent literature is discussed. Many minor connections have been omitted in this list. From those included the following generalizations may be made:

1. Optic tract fibers (stratum opticum, fig. 6) enter the reptilian optic tectum very close to the surface, in many reptiles at the periphery of the area. The number, and consequently the richness of distribution, depends upon the development of the peripheral visual system in the reptile considered.

\footnotetext{
${ }^{1}$ In the 1934 paper an unfortunate confusion in listing the labels appears to interchange some of the layers on the figures. The text, however, is in perfect agreement with that of the $1933 \mathrm{a}$ and $1933 \mathrm{~b}$ papers.
} 
2. Stratum griseum et fibrosum superficiale and stratum griseum centrale (fig. 6) are regions of reception for a wide range of sensory impulses: (1) from the retina by way of the optic system; (2) from the dorsal thalamus by thalamo-tectal bundles; (3) from the spinal cord and the brain stem by ascending lemnisci paths (such as the spino-mesencephalic tract and the secondary ascending system of $\mathrm{V}$ or trigeminal lemniscus). The optic tract fibers enter stratum opticum but the terminal fascicles spread into the underlying layers, as far as stratum album centrale (profundum). The wide spread of the optic fibers over the surface of the optic tectum and their termination at various levels indicate the markedly important part this region plays in reptiles as a visual-somatic and visual-visceral sensory correlation center. That there is a localization pattern projected by the optic tract on the reptilian optic tectum, similar to that seen in mammals, seems probable, but needs verification. The afferent tracts enter at different levels. (Huber and Crosby, '33 a), whether the depth of the optic tectum or its rostrocaudal extent be taken into account, thus contributing somewhat to the typical stratification of cells and fibers in the layers under consideration. However, the fiber layers between the rows of neurons constituting the various secondary bands of stratum griseum et fibrosum superficiale represent also both regions of synapse between the processes of neurons of the different, and sometimes adjoining, gray bands and between those of different strata (figs. 4 and 6).

3. The forward projection of pain and temperature impulses from the body and the head via the optic tectum upon the dorsal thalamus is one of the characteristic patterns of the reptilian brain. Thus, in reptiles, a very considerable proportion of sensory impulses brought forward from the brain stem and spinal cord levels by the spino-mesencephalic or tectal tract, forerunner of both the spino-tectal and spinothalamic systems, and by the ventral secondary ascending tract of $V$, reach the dorsal thalamus after a synapse in the optic tectum, the upper neurons in the system constituting 
tecto-thalamic bundles. In reptiles, then, and in birds also (Huber and Crosby, '29), there is a direct relation between the elaboration of the pattern of the dorsal thalamus and that of the optic tectum, particularly of its receptive layers superficial to stratum album centrale. There is a foreshadowing of a sensory projection pattern on the reptilian tectum exhibited in the layering of its receptive areas and the more limited connections of certain of the constituent neurons of each area and in the dorsoventral and rostrocaudal regional distribution of entering sensory systems. Nevertheless, tectothalamic paths relaying such ascending impulses to the dorsal thalamic nuclei could not possibly establish in these diencephalic centers a localization pattern comparable in degree to that found in lower mammals (Le Gros Clark, '29, and others), and even less than seen in primates (Walker, '38 and elsewhere; Woodburne, '39, and various other investigators). In the first place, with the wide distribution of optic fibers, it seems probable that nearly all non-optic impulses must be correlated in the optic tectum with those entering over the optic tract, providing this latter system is stimulated. Moreover, only part of the neurons in stratum griseum et fibrosum superficiale and stratum griseum centrale have fairly limited connections with cells of their own and other layers as will be evident from figure 4 . Chains of cells are present through these strata, so interconnected that they can provide for fairly specific conduction through the optic tectum, but many other neurons of these areas show a wide spread of dendrites which come into contact with entering fascicles at various levels, presumably providing the anatomical basis for the conduction of generalized, rather than specific, impulses. Likewise, the neurons constituting the periventricular stratum have very long dendrites which spread toward the periphery of the brain, and consequently they are under the influence of a wide range of sensory impulses. The neuraxes, like those of many neurons of the layers overlying stratum album profundum, enter outgoing tectal paths. They act, then, as cells of origin for final common paths. These are direct descendants 


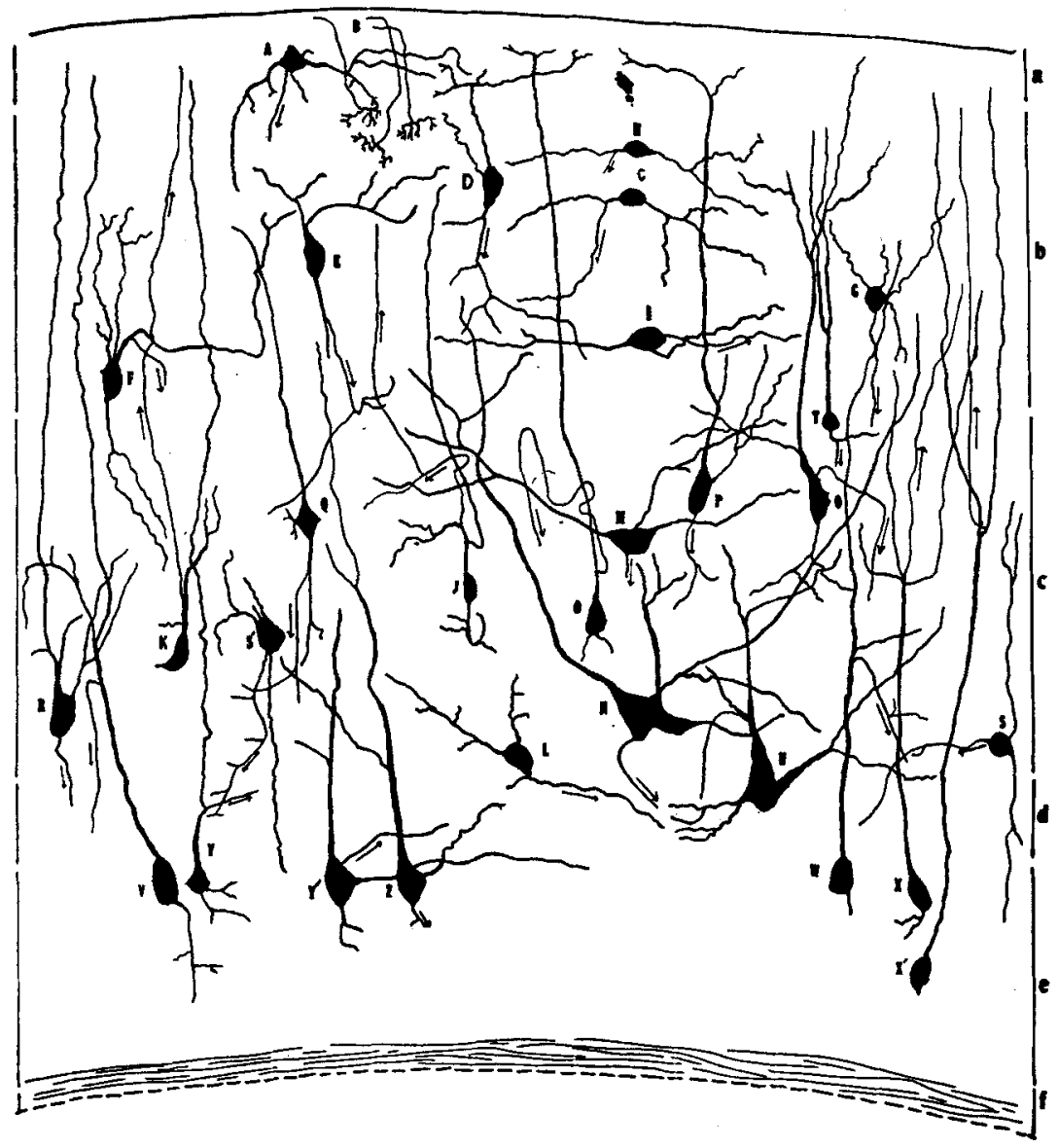

Fig. 4 A figure prepared from Golgi preparations of the optic tectum of Pseudemys elegans. The representative typical neurons of the region were drawn separately by use of the camera lucida and then arranged in their respective strata in a single field. This figure is from the Huber and Crosby paper (' 33 a). It is also in the Ariëns Kappers, Huber and Crosby text, vol. 2, p. 979. a, stratum opticum; b, stratum griseum et fibrosum superficiale; $c$, stratum griseum centrale; $d$, stratum album centrale; e, stratum griseum periventriculare; $f$, stratum fibrosum periventriculare. $\times 200$. 
of the primitive central gray and, like it, have too wide relationships to incoming systems to play any important part in a specific pattern of tectal localization.

In these reptilian forms, then, there is a curious dual representation of pattern - one pattern nonspecific for generalized responses and the other more specific, serving as a basis for possible thalamic localization. The existence of this double set-up is in line with the observation of Herrick (' $41 \mathrm{a}$, ' $41 \mathrm{~b}$ ) on fishes and amphibians, in which a somewhat specific pattern of optic distribution is superimposed upon a nonspecific arrangement of many optic fascicles. Other parts of the optic system, such as the retina (see Polyak's, '42, account of midget bipolar and other bipolar neurons of the inner nuclear layer) and the visual cortex (O'Leary, '41), show this arrangement for the establishment of more sharply localized projections in conjunction with a less specific arrangement of neuron interconnections. It should be emphasized that the complicated neuron pattern in the reptilian optic tectum (fig. 4), with its series of neuron chains, provides also for the summation of impulses by discharge and redischarge through a single neuron or through a series of neurons (see also Pedro Ramón, 1896).

Although pain, temperature and tactile impulses, important in fundamental protective reflexes, end in considerable amounts in the optic tectum of birds and reptiles (a few, however, may reach the caudal end of the dorsal thalamus directly, see Herrick, '33, for amphibians) there is some provision for the projection of more specialized, discriminatory impulses directly to higher centers. References to direct projection of such impulses from certain reptilian and avian bulbar centers upon regions rostral to the optic tectum have been made by various investigators, although there is not complete agreement among them as to the course nor the termination of such connections. Crossed and uncrossed quinto-frontal tracts from the chief sensory nucleus of $\mathrm{V}$ to striatal areas have been described by numerous students of avian material (Wallenberg, '03; Schroeder, '11; Huber and Crosby, '29; Woodburne, 
'36, and others). These fibers carry tactile impulses, including those of more specialized types, from this nucleus directly to higher centers. A similar connection has been described by Woodburne ('36) in certain reptiles. This tract may well be the forerunner of the mammalian dorsal secondary ascending tract of $V$, as this last mentioned author and Ariëns Kappers, Huber and Crosby ('36) have suggested, although its thalamic connections, if present, have not been clearly demonstrated. Bulbo-thalamic fibers, forerunners of the medial lemniscus, turn forward from the small posterior column nuclei (nucleus gracilis and nucleus cuneatus) to form a primordial medial lemniscus in reptiles (Christensen, '27; TIuber and Crosby, '26; Shanklin, '30). This system has been traced to the midbrain tegmentum where it has been lost in the wealth of fibers which characterize the region. It is probable that it reaches the dorsal thalamus in reptiles. Papez ('35) stated that, in the turtle, bulbo-thalamic fibers attain the dorsal thalamus the rudimentary ventral nucleus of his interpretation. Wallenberg ('04 b) described bulbo-thalamic fascicles to nucleus rotundus and to other diencephalic centers in birds. This comnection, which is very probable, but which needs further verification, is to be regarded as an avian medial lemniscus. The appearance in submammals, as in mammals, of tracts such as the quinto-frontal and the medial lemniscus, or their mammalian equivalents or substitutes, is dependent upon the development of specialized tactile and proprioceptive nerve terminations and is coordinated centrally with the differentiation of a rich dorsal thalamic nuelear pattern and elaborate striatal areas in the submammals or cortical areas in the mammals.

The periventricular gray of the reptilian optic tectum is a region of reception for hypothalamo-tectal fascicles by way of the diencephalic-periventricular system (Huber and Crosby, '33 a), or tecto-hypothalamic portion of the dorsal longitudinal fasciculus (Crosby and Woodburne, '40). This periventricular region of the midbrain receives also acoustico- 
optic fibers from the inferior colliculus and fascicles from the cerebellum.

4. Stratum album profundum is the main efferent layer of the optic tectum in reptilian, as it is in most other vertebrate brains. In this stratum, or through associated fascicles overlying it in stratum griseum centrale (or profundum), run most of the tecto-fugal paths. These paths either pass forward to the pretectal areas and dorsal thalamus or ventralward and caudalward to efferent centers of the ventral thalamus, the brain stem and the cerebellum.

5. Attention should be called here to those portions of the dorsal and ventral supraoptic commissural systems (Huber and Crosby, '26 and '33 a) which, in reptiles (as in amphibian and avian forms), provide crossed and uncrossed connections between the optic tectum on the one hand and the base of the diencephalon and tegmental areas of the midbrain on the other hand and also rich intertectal connections. These are a part of the correlating and discharge mechanisms of the reptilian brain.

6. It seems probable that the likeness in nuclear pattern throughout the reptilian optic tectum, as seen either in crosssectioned or longitudinally-cut material, is a reflection of its common efferent character, comparable in significance to the likeness in pattern exhibited by the cerebellar cortex. There is some evidence (to be published later, in connection with that portion of this series of papers devoted to the fiber eonnections of the midbrain and isthmus) that there is an efferent localization pattern in both reptilian and mammalian optic tecta.

THE RELATIONS OF THE OPTIC TECTUM TO SUPERIOR AND INFERIOR COLLICULAR REGIONS IN REPTILES AND MAMMALS

The gray of the optic tectum or superior colliculus shows interesting relations to that of the inferior colliculus, particularly in view of the phylogenetic history of the latter area. In many forms below mammals, for example in certain reptiles, the midbrain end station of the lateral lemniseus is 


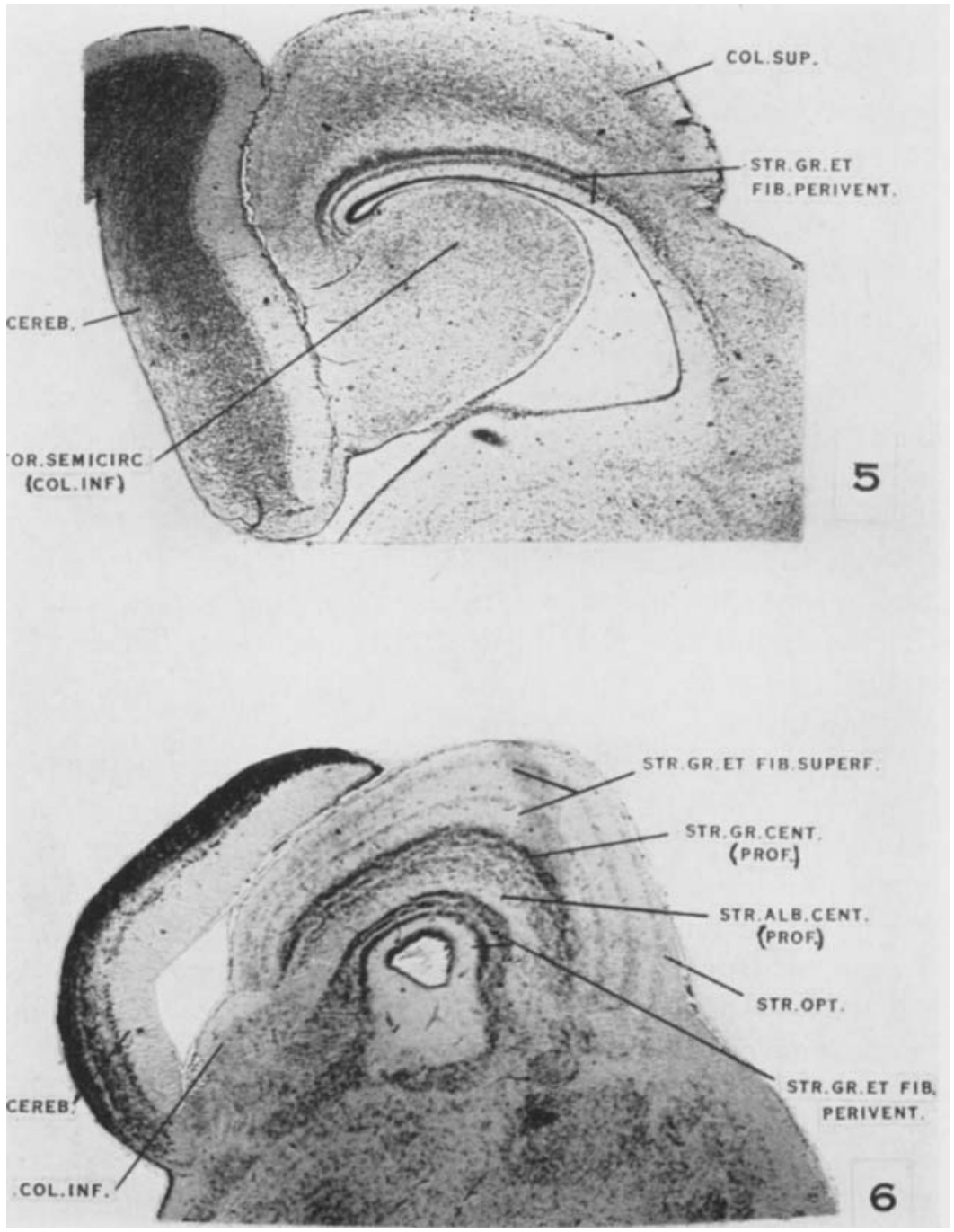

Fig. 5 Photomicrograph of a longitudinal section through the brain of the alligator, to illustrate the position of the torus semicireularis or inferior collieulus. Toluidin blue preparation. $\times 15$.

Fig. 6 Photomicrograph of a sagittal section through the brain of the lizard, Anolis carolinensis, to illustrate both the lamination of the optic tectum and the position and relations of the inferior collieulus. Toluidin blue preparation. $\times 50$. 
generally recognized as a mass of gray, projecting into the ventricle, to which the name of torus semicircularis (or sometimes corpus inferius or corpus posticum) is applied. This gray mass is directly continuous with the periventricular gray of the optic tectum around the angle of the ventricle and has the appearance, in adult material, of being a differentiation of the mesencephalic periventricular gray. The present writers are aware that Palmgren ('21), studying the development of these centers in certain vertebrates, reached the conclusion that torus semicircularis is not the direct homologue of the mammalian inferior colliculus. They are not prepared to discuss the embryological development of the inferior colliculus at this time but they do believe, as have certain other students of the reptilian brain, that torus semicircularis is the homologue of the mammalian inferior colliculus. The reptilian torus semicircularis may project into the ventricle as in the alligator, in which it occupies a subtectal position (fig. 5) or may form an eminence or inferior colliculus on the surface of the midbrain as occurs in snakes and lizards (fig. 6 ; see also Ariëns Kappers, Huber and Crosby, '36, figure 475). The main mass of the mammalian inferior colliculus bulges outward on the dorsal midbrain surface but its rostral pole projects forward in certain mammals (for example in the horse and the sheep; see figures 15 and 24 in the Gillilan contribution on ungulates in this series of papers) into a decidedly subtectal position. The morphologic and functional relations of the reptilian torus semicircularis to the optic tectum approximate very closely those of the inferior colliculus to the superior colliculus of mammals. This is illustrated best by comparing the relations found in such reptiles as the alligator and the lizard, Anolis (figs. 5 and 6; also Huber and Crosby, '26 and '33 a) with those seen in some mammals (mouse, fig. 7). The alligator (fig. 5) torus semicircularis or inferior colliculus is an enlargement of the subtectal gray projecting into the ventricle, corresponding in position to the mammalian pars lateralis of the central gray. It is covered over in large part by fiber fascicles which are a continuation of stratum album 
centrale (profundum). In Anolis (fig. 6) torus semicircularis forms an eminence at the caudal end of the tectal area and corpora quadrigemina can be demonstrated. In such a lizard each of the more caudal of these eminences is an ovoid enlargement of the periventricular gray, originally subtectal in position, which is contimuous with the tectal periventricular

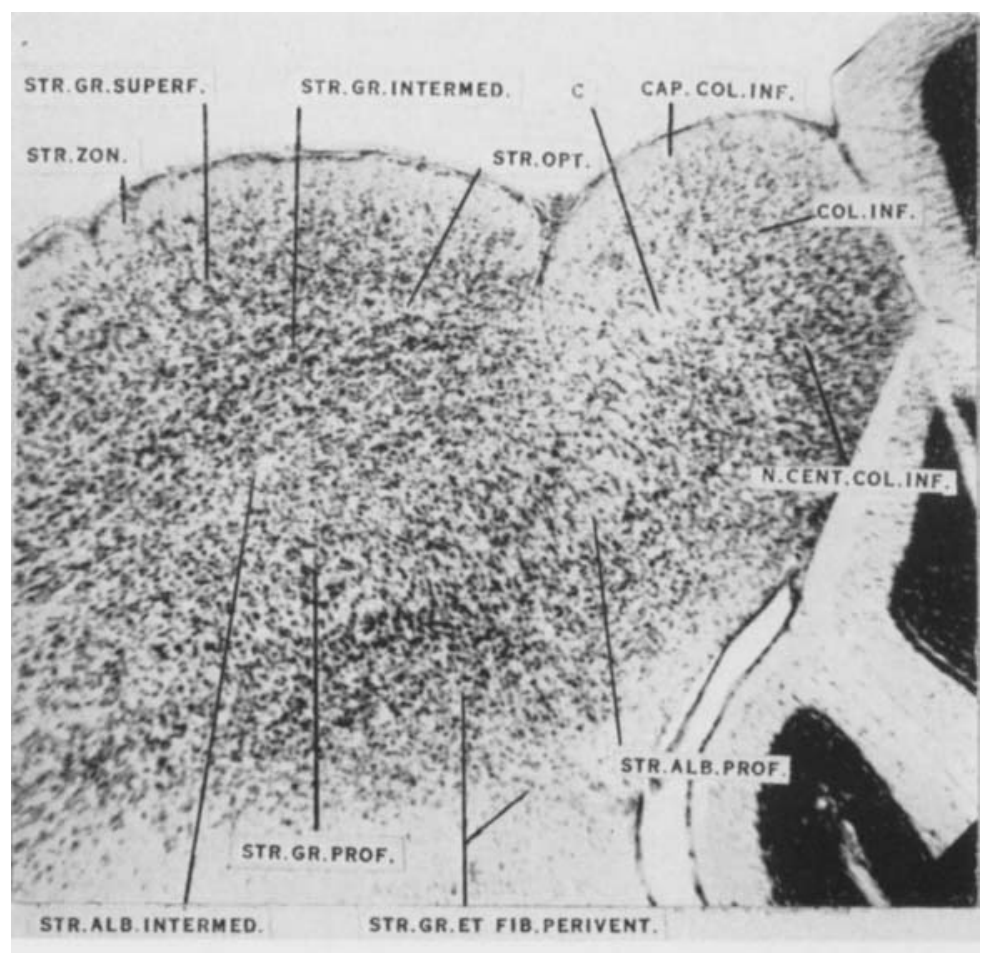

Fig. 7 Photomicrograph of a sagittal section through the brain of the mouse, showing the tectal lamination in this rodent and also the relations of superior and inferior collicular gray. Toluidin blue preparation. $\times 50$.

gray. Over this enlargement are fiber fascicles and narrow cell strands continuous forward with the tectal gray superficial to stratum album centrale (profundum). Essentially similar relations are found in mammals, as will be evident from the following account. 
Sagittal sections taken near the midline of the opossum brain indicate clearly that the central nucleus of the inferior' colliculus is an enlargement of the periventricular gray and is directly continuous frontally with its pars dorsalis (fig. 8) which constitutes stratum griseum periventriculare of the optic tectum. Slightly farther lateralward the central nucleus passes over ventrally into pars lateralis of the central gray (fig. 9). Caudally, the central nucleus of the inferior colliculus (fig. 8) spreads toward the thin anterior medullary velum. At such levels, the caudal end of pars lateralis spreads along its medial surface (fig. 10, for opossum, Woodburne, '43). External to the central nucleus is a band of white which caps the dorsal surface for some distance but, at this level, does not continue along its caudal border. This band, the caudal continuation of stratum album profundum, is overlaid by a strand of gray, the prolongation into the inferior collicular layers of stratum griseum profundum. External to this gray, which passes over directly into that of the central nucleus, are narrower laminae of cells and fibers overlying the dorsal and dorsocaudal surfaces of the main inferior collicular mass. These narrower strands are likewise continuous with optic tectal strata (stratum album intermediale and stratum griseum intermediale). In a sense these strata form a capsule over the dorsal surface of the central nucleus of the inferior colliculus. At the surface of the inferior collicular eminence is a very narrow, inconspicuous band with a few cells in it. Neurons of the mesencephalic root of $V$, which lie at the outer border of the periventricular gray in upper portions of the midbrain, are situated, at lower midbrain levels, along the periventricular margin of the inferior colliculus or occasionally within its central nucleus (fig. 9). Followed lateralward in the series, the broad band of white and gray, which carries commissural (and efferent) fibers and which is the caudal continuation of stratum album profundum and associated neurons, decreases so that it has only slight representation as a layer except at the most cephalic end of the inferior colliculus in the intercollicular region (fig. 9). 


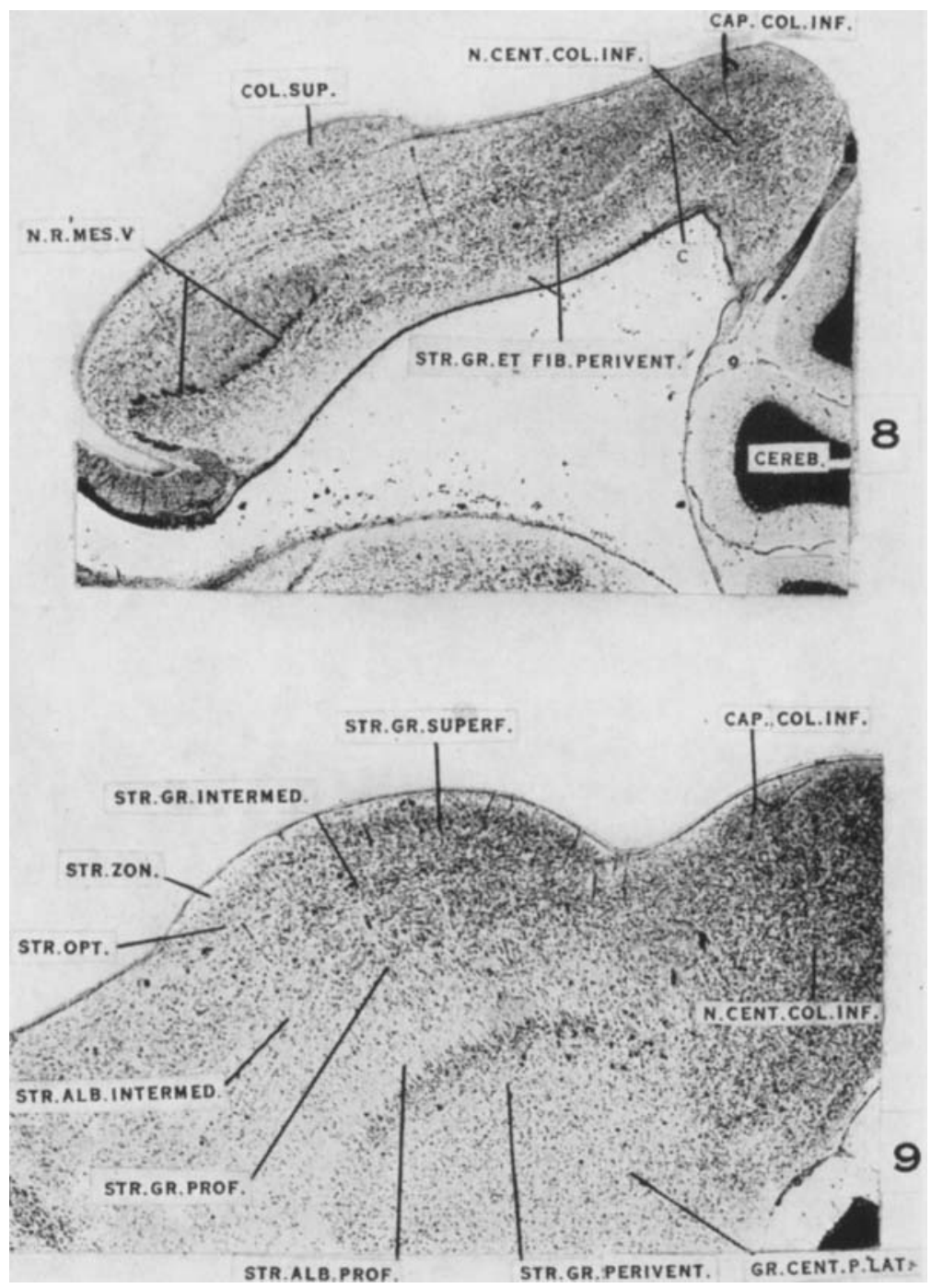

Fig. 8 Photomicrograph of a sagittal section through the tectal regions of the midbrain of the opossum. The plane of the section is not far from the midline. Toluidin blue preparation. $\times 15$.

Fig. 9 Photomierograph of a sagittal section from the same series as that illustrated in figure 8 , but slightly farther lateral. $\times 15$. 
The remainder of the eminence is occupied by the central nucleus of the inferior colliculus (which contributes fibers to the previously mentioned white), bordered dorsocaudally and dorsally by a narrow band with a few scattered cells continuous with those of stratum griseum intermediale and stratum album intermediale. Ventrally, at this level, the inferior collieular gray still lies in relation with stratum griseum periventriculare of the optic tectum (although differentiable by slight differences in the staining qualities of its constituent neurons) and with the underlying pars lateralis of the mesencephalic central gray, of which it probably represents an enlargement. Still farther lateralward, the optic tectal periventricular gray becomes greatly reduced and ultimately disappears, although even before its disappearance it is separated from the chief nucleus of the inferior colliculus by fiber fascicles (the efferent systems from the optic tectum) as they swing ventralward and ventrocaudalward (fig. 10). At these more lateral levels, the central nucleus of the inferior colliculus consists of a long ovoid mass of relatively closely packed, multipolar cells of angular or stellate character. These are mostly small to medium-sized cells but occasional large, multipolar neurons are present. There is a marked continuation of stratum griseum profundum, stratum album intermediale and stratum griseum intermediale over the upper surface of the central nucleus of the inferior colliculus to form a capsule about it. There is no clearly demarcated white layer intervening (only traces of a caudal continuation of stratum album profundum) and the gray strands interconnect these outer layers with the central nucleus (fig. 10). Toward the lateral border of the inferior colliculus, as the central nucleus reduces in size, there appears to be a caudal encroachment of efferent tectal tracts. These are much less evident but in approximately the position occupied by the caudal extension of stratum album profundum farther medialward. They are efferent fascicles from the inferior colliculus which will assemble with those from superior collicular levels. 


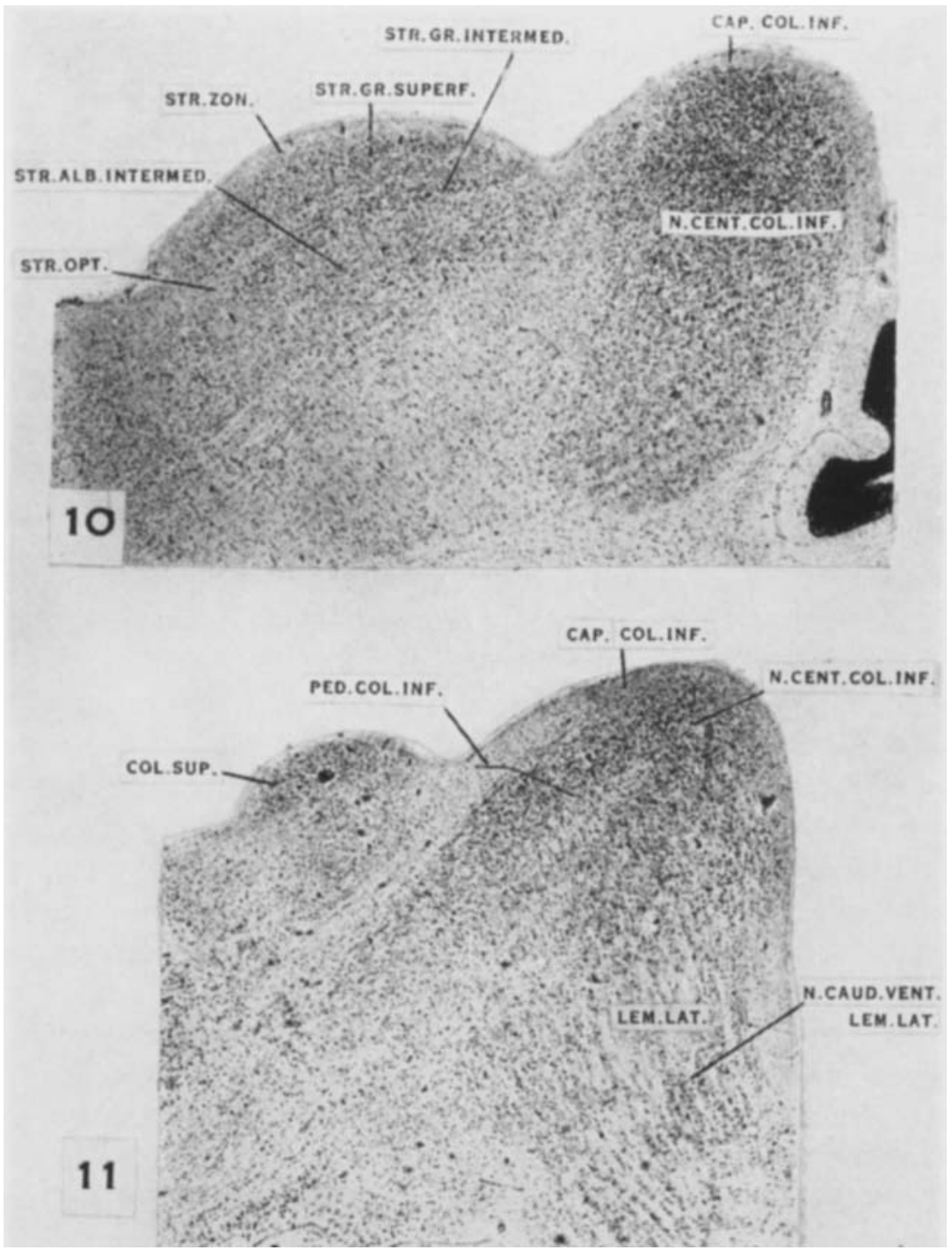

Fig. 10 Photomicrograph of a sagittal section from the same series but farther lateralward than that illustrated in figure $9 . \times 15$.

Fig. 11 Photomicrograph of a sagittal section through the lateratpart of the inferior colliculus. This illustration was made from the same series as that used for figures 8,9 and $10 . \times 15$. 
Along the dorsolateral and lateral surfaces of the inferior colliculus is a large band of fibers, the peduncle or brachium of the inferior colliculus (fig. 11). Fascicles of the lateral lemniscus (fig. 11) enter the base of the central nucleus and, to some extent, pass along its medial border, but many of them swing lateralward, along the outer part of this nucleus, turning in for termination. External to these fiber's is the gray capsule and then a zone with only occasional cells. Most of the fibers enter the central nuclens, but some may end on the surrounding cells. Transverse sections show particularly well the distribution of the lateral lemniscus to the caudal part of the inferior colliculus. The fibers approach its base and then swing lateralward in large numbers, but also caudalward and medialward, as well as entering it directly.

The relations here described for the opossum have been documented for the rabbit, the rat, the mouse, the bat, the shrew, the cat, the dog, the mink, the horse, the sheep and, somewhat less perfectly, for the monkey. Throughout the subprimate series the direct continuity of stratum griseum periventriculare of the optic tectum (pars dorsalis of the central gray) and, in most of the forms studied, of pars lateralis of the central gray with the central nucleus of the inferior colliculus is clearly evident. So also is the continuity over the central nucleus of the inferior colliculus of stratum album profundum and the gray layers intervening between this stratum and stratum opticum. These more superficial layers of the optic tectum or superior colliculus form an incomplete gray and white capsule for the chief nucleus of the inferior colliculus.

The primate material, because of the plane of section of the available preparations, is not quite so favorable for establishing the finer relations between the superior and inferior portions of the midbrain roof. In the macaque series, all the essential relations were established. In man the evidence for this pattern common to most mammals is not entirely satisfactory, complete verification of the continuity of the superior collicular strata into the gray and white bands encapsulating 
the central nucleus of the inferior colliculus not being clearly obtainable from the available series. The writers are of the opinion that the inability to establish complete homologies in man is due to the inadequacy of the material rather than to differences in fundamental pattern.

The relative size of the superior and inferior colliculi in a given mammal is in proportion to the development of the eyes and the cochlear portions of the ear, respectively. Thus the superior colliculus is larger than the inferior in the monkey, which has large eyes, but reduced in the bat in which the visual apparatus is less well developed than the auditory. The amount of inferior collicular gray visible from the brain surface is not always an exact guide as to the actual development of the inferior collicular complex, however, for in some mammals, for example in the sheep and the horse (see figs. 15 and 24 in the Gillilan article in this series of papers) the rostral pole of the inferior colliculus is thrust forward beneath the superior colliculus toward the periventricular gray, in a relation approaching that extibited by the inferior collicular gray in certain reptiles.

\section{COMPARISON OF THE MAMMALIAN AND REPTILIAN TECTAL REGIONS}

From the foregoing accounts of the reptilian and mammalian optic tecta, certain likenesses and certain differences may be summarized. Table 3 gives a comparison of the tectal layers in these forms.

An understanding of the embryonic development of the mammalian optic tectum is valuable for a comprehension of the relations between mammals and submammals. The mammalian optic tectum, like the remainder of the vertebrate neural tube, begins embryologically as an area of central gray bordered by a non-cellular zone. Barnard ('38) showed that, during embryonic development, cells migrate toward the periphery and thus the successive layers are formed. At the appropriate stage, the optic fibers lie near the surface, no superficial gray layer being present. Then, as other por- 
tions of the nervous system develop, the cells migrate superficial to stratum opticum to form stratum griseum superficiale. This migration is probably in response to the neurobiotactic functioning of the external cortico-tectal tract. Such a migration would not and does not appear appreciably in submammals which lack this system.

At no time does the mammalian optic tectum show the high secondary differentiation which characterizes it in reptilian and avian forms. Neither does this region in mammals play an important part in the projection of ascending sensory systems upon the dorsal thalamus nor exhibit specialization in

TABLE 3

Reptiles

Hamals

Stratum zonsle............... Stratum zonkle

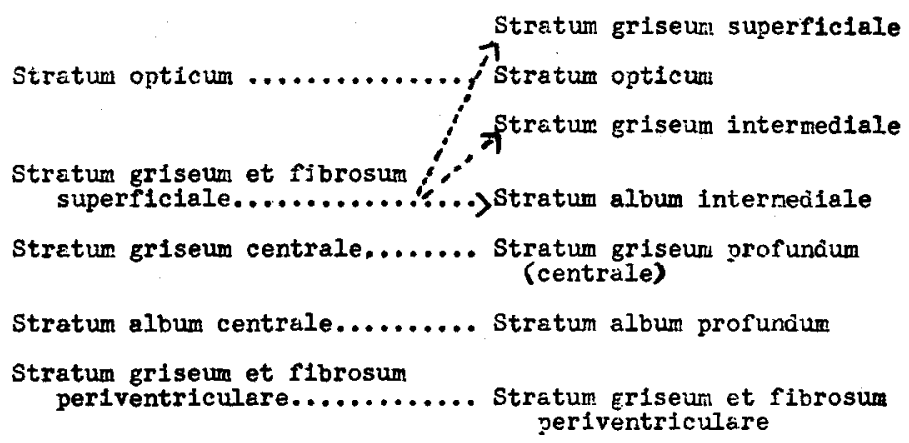

forms having the most highly differentiated nuclear pattern in this part of the diencephalon. It is suggested that these facts - the lack of differentiation within this part of the tectum and its minor importance as a region of synapse for ascending systems to the dorsal thalamus - are correlated.

To conclude: (1) the arrangement in the mammalian optic tectum is a modification of the six-layered pattern common to all vertebrates; (2) its change to a nine-layered pattern is secondary and a reflection of the shift in function of the optic tectum from an important way-station to the dorsal thalamus, to a significant center in the extrapyramidal system. With this change, the secondary lamination, which often character- 
izes important sensory correlation areas, disappears and a rearrangement related to its significant cortico-tectal systems develops; (3) the cell and fiber patterns, common to mammalian and reptilian forms, are those which reflect the functional significance of this region as a reflex center, set off by visual, visual-somatic and visual-visceral impulses.

4. In both reptiles and mammals, the optic tectum is an important way-station in the visual reflex paths. The superior collicular regions are major regions of termination for optic tracts, serving as correlation centers for visual with other somatic and visceral impulses and as nuclei of origin for efferent systems to motor centers of the brain stem and spinal cord.

5. The pattern of tectal efferent paths laid down in submammals is much the same in mammals, with the exception of the tecto-geniculate system. This is present as an efferent path from the tectum in reptiles and lower mammals. The tecto-geniculate tract passes to the ventral nucleus of the lateral geniculate (which belongs to the ventral thalamus or subthalamus) and from this nucleus, by way of fasciculus geniculatus descendens (Beccari, '23; Huber and Crosby, '26, and others for reptiles; Ariëns Kappers, Huber and Crosby, '36 for reptiles and mammals; Bodian, ' 40 , for mammals), to efferent centers of the brain stem. In those higher mammals in which no ventral nucleus is present, or only represented by vestiges, the authors have not demonstrated this tract.

6. In reptiles, but not in mammals, the optic tectum is an important constituent of the pathway for the projection of ascending sensory systems from the brain stem and the spinal cord on to the dorsal thalamus, and shows a coordinate development. The impulses from the two sides are interrelated through commissural systems, including those in the intertectal (or dorsal) commissure and those of the supraoptic system. In mammals, the major ascending afferent systems pass directly to the dorsal thalamus and neither outstanding tecto-thalamic tracts nor marked secondary lamination of the receptive strata of the mammalian optic tectum are 
evident. Moreover, the tectal commissural portions of the supraoptic system are reduced or entirely lacking in mammals.

7. In mammals, but not in reptiles, the optic tectum is an important way-station in the extrapyramidal system. Obviously such a function -would not be possible in reptiles in which the cortical areas are so much less developed and cortico-tectal tracts have not been demonstrated.

8. The mammalian inferior colliculus and its reptilian homologue, the torus semicircularis or inferior colliculus (Huber and Crosby, '26, '33 a, and others), which are the chief midbrain centers of termination of the lateral lemniscus, show like morphologic relations and are both derivatives of the periventricular gray. In both reptiles and mammals the chief nucleus is directly continuous with the periventricular gray of the optic tectum and is encapsulated by a continuation of the overlying strata of this superior collicular region, the stratum album centrale or profundum with the gray and white layers as far as the optic tract. The reptilian torus semicircularis or inferior colliculus is an enlargement of the subtectal periventricular gray corresponding to pars lateralis of the central gray in mammals. This pars lateralis is continuous in many mammals at least (see the various accounts of its relations in the other papers of this group) with the chief nucleus of the inferior colliculus. It may contain corticotectal fibers (compare Mettler, '32, and Barris, Ingram and Ranson, '35) which have reached it via the superior colliculus. Their presence might account for the peripheral position of the neurons encapsulating the chief nucleus which have certainly migrated from the central gray of the region.

9. There are fundamental differences in the morphologic patterns characterizing the superior colliculus or the optic tectum and the inferior colliculus whether reptilian or mammalian brains are considered. These differences illustrate two ways in which the development of higher correlation centers may occur within the nervous system of either reptiles or mammals. The chief nucleus of the inferior colliculus, an enlargement of the periventricular gray, increases in amount 
but not in complexity of pattern with an increase in ascending auditory paths. The superior collicular pattern is a secondary differentiation from the primitive periventricular gray through the peripheral migration of neurons during embryonic development to form the layers external to the main efferent layer, stratum album profundum. Such migrations occur embryologically and probably phylogenetically under the influence of afferent tectal tracts and the morphologic pattern produced reflects the richness of the connections and permits, within certain limits, the morphologic localization of such entering systems. The superior collicular layering in mammals, and more particularly in reptiles, favors localization (although such localization is not in perfected form) and permits specificity of reception and projection of impulses. The inferior collicular pattern gives much less morphologic evidence for a localization pattern for entering impulses, except for any in the small capsular portion directly related to the receptive layer of the superior colliculus. It is suggested that increase in the inferior collicular gray will not increase the specificity of conduction through it but rather the amount of such conduction in terms of the neurons and afferent and efferent fibers involved.

These two methods of accenting the importance of higher sensory correlation centers - (1) by spreading the gray out into thin cortex-like layers or (2) by increasing the amount to form a massive structure - can be illustrated in other brain regions. Thus in the cortex of mammals the layer arrangement is associated with a localization pattern which makes for specificity of reception and response. The exaggerated striatal regions of birds (Edinger, Wallenberg and Holmes, '03; Rose, '14; Huber and Crosby, '29; Craigie, '30, '32, and elsewhere; Durward, '32 and '34, and many others) - the hyperstriatal and neostriatal areas projecting into the lateral ventricle - whether one regards them as cortical or as serving wholly or in part as vicarious cortex, do not lend themselves so well morphologically to the spreading out of entering fibers. They would likewise favor less well specificity of reception and finer localization of impulses. 